\title{
Growth and Growth Factors
}

\author{
Evelien F. Gevers ${ }^{\mathrm{a}, \mathrm{b}}$ and Mehul T. Dattani ${ }^{\mathrm{a}}$ \\ aDevelopmental Endocrine Research Group, Clinical and Molecular Genetics Unit, Institute for Child Health, \\ London, and bDivision of Molecular Neuroendocrinology, National Institute for Medical Research, \\ London, UK
}

\begin{abstract}
The last year has again seen some major advances in the Growth and Growth Factors field. Significant advances have been made in our understanding of the genetics of growth. For example, mutations in the pericentrin gene PCNT are associated with both primordial dwarfism and Seckel syndrome. Critically, these genes link DNA repair processes to growth. The identification of RNF135 brings into the field a novel gene implicated in growth. Additionally, genome-wide association studies have led to the identification of a number of loci that are implicated in normal growth. These include genes implicated in the Hedgehog signaling pathway and cell cycle regulation. These discoveries go some way towards explaining the genetic variation in height, but their importance may lie in other areas as well, for example cell cycle regulation. In addition, progress has been made in our understanding of Noonan syndrome by the discovery of further gene abnormalities in patients with this condition. Genetic mutations can now be identified in the majority of patients. Fundamental work has shown the importance of growth factor receptors in stem cell proliferation and differentiation, and the molecular mechanism behind activating growth factor receptor mutations. Some items are always on the growth factor research agenda, like direct and indirect actions of $\mathrm{GH}$, the role of nuclear $\mathrm{GHR}$ and clinical effects of IGF1 but important new data have increased our understanding over the last year. We have attempted to discuss some of the key papers that have been published in this field.
\end{abstract}

\section{Mechanism of the year}

\section{IGF and FGF cooperatively establish the regulatory stem cell niche of pluripotent human cells in vitro}

Bendall SC, Stewart MH, Menendez P, George D, Vijayaragavan K, Werbowetski-Ogilvie T, Ramos-Mejia V, Rouleau A, Yang J, Bosse M, Lajoie G, Bhatia M

McMaster Stem Cell and Cancer Research Institute, Michael G. DeGroote School of Medicine, and Department of Biochemistry, McMaster University, Hamilton, Ont., Canada

mbhatia@mcmaster.ca

Nature 2007;448:1015-1021

Background: Distinctive properties of stem cells are not autonomously achieved, and recent evidence points to a level of external control from the microenvironment. Here, the authors demonstrate that self-renewal and pluripotent properties of human embryonic stem (ES) cells depend on a dynamic interplay between human ES cells and autologously derived human ES cell fibroblast-like cells (hdFs).

Results: Human ES cells and hdFs are uniquely defined by insulin-like growth factor (IGF) and fibroblast growth factor (FGF) dependence. IGF1 receptor (IGF1R) expression was exclusive to the human ES cells, whereas FGF receptor 1 (FGFR1) expression was restricted to surrounding hdFs. Blocking the IGF2/IGF1R pathway reduced survival and clonogenicity of human ES cells, whereas inhibition of the FGF pathway indirectly caused differentiation. IGF2 is expressed by hdFs in response to FGF, and alone was sufficient in maintaining human ES cell cultures.

Conclusion(s): This study demonstrates a direct role of the IGF2/IGF1R axis on human ES cell physiology and establishes that hdFs produced by human ES cells themselves define the stem cell niche of pluripotent human stem cells.

Using proteomic identification, fractionation of human ES cell cultures and receptor localization combined with functional in vitro and in vivo assays to characterize human ES cell properties, this article reveals a previously unappreciated but essential cellular interplay that establishes paracrine signaling as 
being required for self-renewal and pluripotency of human ES cells. These elegant experiments help to understand why stem cells are able to continue to proliferate and remain in an undifferentiated state. The propagation of ES cells was previously known to require the magic supplementation with basic fibroblast growth factor (bFGF). The authors show that stem cells exclusively express IGF1 receptor whereas more differentiated cells derived from the stem cells and surrounding the stem cells (hdFs) exclusively express FGFR1. By producing IGF2, in response to FGF, the hdFs support survival of the stem cells. A balance can thus be maintained that allows for proliferation of stem cells.

\title{
Clinical trials, (not so) new treatment
}

\section{Long-term treatment with recombinant insulin-like growth factor (IGF)-1 in children with severe IGF1 deficiency due to growth hormone insensitivity}

\author{
Chernausek SD, Backeljauw PF, Frane J, Kuntze J, Underwood LE \\ Department of Pediatrics, University of Cincinnati College of Medicine, Cincinnati Children's Hospital Medical Center, \\ Cincinnati, Ohio, USA \\ steven.chernausek@cchmc.org \\ J Clin Endocrinol Metab 2007;92:902-910
}

Background: Children with severe GH resistance due to congenital or acquired defects in GH action have short stature that cannot be remedied by GH treatment. The current study examined the long-term effects of recombinant human IGF1 (rhIGF1) treatment for short children with severe IGF1 deficiency. Methods: 76 children with GH insensitivity were treated with rhIGF1 for up to 12 years in a predominantly open-label design study. Entry criteria included age older than 2 years, SD scores for height and circulating IGF1 concentration $<-2$ for age and sex, and evidence of resistance to GH. rhIGF1 was administered subcutaneously in doses between 60 and $120 \mu \mathrm{g} / \mathrm{kg}$ twice daily.

Results: Height velocity increased from $2.8 \mathrm{~cm} /$ year on average at baseline to $8.0 \mathrm{~cm} /$ year during the first year of treatment $(\mathrm{p}<0.0001)$ and was dose-dependent. Height velocities were lower during subsequent years but remained above baseline for up to 8 years. The most common adverse event was hypoglycemia, which was observed both before and during treatment in $49 \%$ of treated subjects. The next most common adverse events were injection site lipohypertrophy $(32 \%)$ and tonsillar/adenoidal hypertrophy $(22 \%)$.

Conclusion(s): Treatment with rhIGF1 stimulates linear growth in children with severe IGF1 deficiency due to GH insensitivity. Adverse events are common but are rarely of sufficient severity to interrupt or modify treatment.

This paper describes the first long-term data from a multicenter study on the efficacy and safety of mesacermin (recombinant human IGF1) in GH resistance, and these data were used by the FDA to approve IGF1 treatment. Earlier studies, in a small number of subjects, showed that IGF1 treatment increased HV in the first year, up to $8-9 \mathrm{~cm}$ and that this effect waned in the subsequent years, but longterm data were lacking. This current study was not controlled optimally (open-label, 5 different study protocols, large dose range (40-120 $\mathrm{g} / \mathrm{kg})$ ) but provides data that were unpublished so far. The study group was large, consisting of children who had developed GH antibodies $(n=9)$, children with GHRD diagnosed on the basis of GHR gene abnormality or absent GHBP $(n=28,23$ with definite GHR abnormality) and GHIS defined as 'clinical features of GHRD', but without confirmation of a GHR abnormality $(n=39) .59$ patients could be assessed for growth, and of those, 14 patients also received GnRH analogue treatment. Pretreatment height velocity was extremely low at $2.3 \mathrm{~cm} /$ year. Mean duration of treatment was $4.4 \pm 3.0$ years. Safety data were collected from only 23 patients. First year height velocity increased in a dose-dependent manner, and reached $8.7 \pm 1.7 \mathrm{~cm} /$ year for those receiving $>100 \mu \mathrm{g} / \mathrm{kg}$ bd. HV stabilized after year 2 at approx. $5 \mathrm{~cm} /$ year. Hypoglycemia occurred frequently before initiation of IGF1 treatment, but IGF1 treatment appeared to increase the number of hypoglycemic events. The authors also performed a very small $(n=5)$ double-blind study where patients received placebo or IGF1 for 6 months, and showed an increased number of hypoglycemic events ( $2.6 \mathrm{vs.} 5.5 \%$ of measurements) although this underpowered part was not statistically significant. Kidney, spleen and thymus size increased, and exceeded +2 SD in a few patients. Tonsillar hypertrophy occurred in $30 \%$ of patients and conductive hearing loss was found in $50 \%$ although it is not known whether this can be attributed to 
IGF1 treatment. This paper provides very important data on IGF1 treatment in children with extremely severe short stature due to severe GH resistance, but questions regarding safety and efficacy in less severe GH resistance remain. Despite FDA and EMEA approval for a surprisingly broad indication (including ISS with low IGF1 levels ( $<3$ SDS)), the small amount of safety data, which are quite short term so far, suggest that this drug should be used with caution, and it is essential that the pediatric endocrine community launches a safety monitoring of every treated patient.

\section{Anastrozole increases predicted adult height of short adolescent males treated with growth hormone: a randomized, placebo-controlled, multicenter trial for one to three years}

Mauras N, Gonzalez de Pijem L, Hsiang HY, Desrosiers P, Rapaport R, Schwartz ID, Klein KO, Singh RJ, Miyamoto A, Bishop K

Nemours Children's Clinic, Division of Endocrinology, Jacksonville, Fla., USA

nmauras@nemours.org

J Clin Endocrinol Metab 2008;93:823-831

Background: Studies of male patients with mutations in the estrogen receptor gene as well as in the aromatase enzyme gene have shown that epiphyseal fusion in both males and females is regulated by estrogen. Theoretically, aromatase inhibitors such as anastrozole which prevent the conversion of androstenedione and testosterone to estrone and estradiol respectively could slow epiphyseal fusion and thereby increase final height.

Methods: 52 adolescent males with GH deficiency treated with GH were treated with anastrozole or placebo daily in addition to $\mathrm{GH}$ as part of a double-blind, randomized, placebo-controlled clinical trial. Results: 50, 41 and 28 subjects completed 12, 24 and 36 months respectively. Linear growth was comparable between groups, but there was a significantly slower in bone age advancement from baseline in the anastrozole group vs. placebo group after 2 years $(+1.8 \pm 0.1$ vs. $+2.7 \pm 0.1$ year, $\mathrm{p}<0.0001)$ and after 3 years $(+2.5 \pm 0.2$ vs. $+4.1 \pm 0.1$ year, $\mathrm{p}<0.0001)$. Predicted adult height increased by $+4.5 \pm 1.2 \mathrm{~cm}$ in the anastrozole group at 24 months and $+6.7 \pm 1.4 \mathrm{~cm}$ at 36 months, whereas the height increment was $1 \mathrm{~cm}$ at both time points in the control group. Tempo of virilization was normal in the boys on the aromatase inhibitor. Estradiol and estrone concentrations increased less in the anastrozole group compared with placebo, although safety data were comparable between groups.

Conclusion(s): Aromatase inhibitors such as anastrozole increase predicted adult height in adolescent boys on GH therapy whilst pubertal progression is normal. Long-term follow-up is required to evaluate the safety and efficacy of this treatment.

There is a real need for randomized placebo-controlled trials to evaluate novel growth-promoting therapies. This study attempts to evaluate the role of aromatase inhibitors in children with GHD and suggests that anastrozole slows the tempo of bone age maturation with an increase in height SDS for bone age and hence predicted final height. However, the study does not provide data on measured final height, and hence treatment with this agent at present remains experimental. The issues of effects on testes, fertility and bone remain unresolved.

\section{New paradigm}

\section{A molecular brake in the kinase hinge region regulates the activity of receptor tyrosine kinases}

Chen H, Ma J, Li W, Eliseenkova AV, Xu C, Neubert TA, Miller WT, Mohammadi M Department of Pharmacology, New York University School of Medicine, New York, N.Y., USA mohammad@saturn.med.nyu.edu

Mol Cell 2007;27:717-730

Background: Activating mutations in the tyrosine kinase domain of receptor tyrosine kinases (RTKs) cause cancer and skeletal disorders. 
Methods and Results: Comparison of the crystal structures of unphosphorylated and phosphorylated wildtype FGFR2 kinase domains with those of seven unphosphorylated pathogenic mutants reveals an autoinhibitory 'molecular brake' mediated by a triad of residues in the kinase hinge region of all FGFRs. Structural analysis shows that many other RTKs, including PDGFRs, VEGFRs, KIT, CSF1R, FLT3, TEK, and TIE, are also subject to regulation by this brake.

Conclusion(s): Pathogenic mutations activate FGFRs and other RTKs by disengaging the brake either directly or indirectly.

Several types of chondrodysplasia (e.g. achondroplasia, hypochondroplasia, thanatophoric dysplasia), as well as several forms of craniosynostosis (e.g. Crouzon syndrome, Pfeiffer syndrome) are due to activating mutations in the tyrosine kinase domain of FGFR2 or FGFR3, and some types of cancer are due to activating mutations in the tyrosine kinase domains of other receptor tyrosine kinases (RTK). This paper reveals a common mechanism whereby these mutations result in constitutive activation of many tyrosine kinase receptors. By comparing molecular structures of phosphorylated active, unphosphorylated inactive and mutant FGFR2, the authors show that mutations in the kinase domain change the molecular structure from the inactive conformation to that of the active structure. They then show that in most RTKs the kinase domain forms a hinge that stops the molecule from adopting an activating conformation, and that mutations result in release of this molecular brake.

\title{
Concepts revised or expanded
}

\section{Loss of sexually dimorphic liver gene expression upon hepatocyte-specific deletion of Stat5a-Stat5b locus}

\author{
Holloway MG, Cui Y, Laz EV, Hosui A, Hennighausen L, Waxman DJ \\ Department of Biology, Boston University, Boston, Mass., USA \\ djw@bu.edu \\ Endocrinology 2007;148:1977-1986
}

Background: The GH secretory profile is a major regulator of growth and hepatic gender-specific cytochrome P450 enzyme expression. This study aimed to clarify the role of hepatic Stat $5 \mathrm{a}$ and $\mathrm{b}$ in this process.

Methods: Hepatocyte-specific, albumin-Cre recombinase-mediated deletion of the entire mouse Stat5aStat $5 \mathrm{~b}$ locus was carried out to evaluate the role of signal transducer and activator of transcription $5 \mathrm{a}$ and $5 \mathrm{~b}($ Stat $5 \mathrm{ab})$ in the sex-dependent transcriptional actions of $\mathrm{GH}$ in the liver.

Results: Whole-liver Stat5ab RNA decreased by approximately $65-85 \%$ in the liver-Stat5ab-deficient mice, and residual Stat 5 immunostaining was observed in a minority of the hepatocytes, indicating incomplete excision by Cre recombinase. Serum IGF1 decreased by $50 \%$ but postnatal growth was unaffected. 20 sexually dimorphic, liver-expressed genes revealed significant down-regulation of 10 of 11 male-specific genes in livers of male hepatocyte Stat5ab-deficient mice. Class I female-specific liver genes were markedly up-regulated (de-repressed), whereas the expression of class II female genes, belonging to the Cyp3a subfamily, was unaffected by the loss of hepatocyte Stat5ab. Stat5ab is thus required in the liver for positive regulation of male-specific genes and for negative regulation of a subset of female-specific genes. Continuous GH infusion strongly induced ( $>500$-fold) the class II female gene Cyp3a16 in both wild-type and hepatocyte Stat5ab-deficient male mice, indicating sex-specific transcriptional regulation by GH that is Stat5ab-independent. In contrast, hepatocyte Stat5ab deficiency abolished the strong suppression of the male-specific Cyp2d9 by continuous GH seen in control mouse liver. Analysis of global Stat5a-deficient mice indicated no essential requirement of Stat5a for expression of these sex-specific liver Cyp genes. In addition, the liver-Stat5ab-deficient mice had normal postnatal body weight gain, despite a $50 \%$ decrease in serum IGF1.

Conclusion(s): The major loss of liver sexual dimorphism in hepatocyte Stat5ab-deficient mice can primarily be attributed to the loss of Stat $5 \mathrm{~b}$ but loss of hepatic Stat $5 \mathrm{ab}$ does not result in abnormal growth.

Evidence is accumulating that $\mathrm{GH}$ has direct actions on peripheral tissues and that JAK2-Stat5 signaling is the major signaling pathway for most GH actions, mutations in STAT5B resulting in severe GH 
insensitivity. This and the next two papers each focus on one 'peripheral' target tissue for $\mathrm{GH}$, to assess the role of GH and/or Stat5 ( $a$ and $b$ ) in that tissue. Cre-LoxP-mediated recombination allows for tissue-specific deletion of DNA that is surrounded by loxP elements, if Cre is expressed in a tissuespecific fashion. Therefore, all three studies used the transgenic Stat5 floxflox mice and these mice were crossed with mice that express Cre either in the liver, skeletal muscle or the brain, using the tissue-specific promoters for albumen, Myf5 and Nestin. Mice models that have reduced production of hepatic IGF1 (LID mice) have normal growth, yet serum IGF1 is $30-50 \%$ of normal, so that the role of circulating IGF1 is difficult to assess. The first paper shows that hepatic Stat5 null (Stat5LKO) mice also display normal growth in keeping with a role for direct GH action or locally produced IGF1 in regulation of growth - however, these mice too have significant circulating IGF1 levels. Despite the incomplete reduction of hepatic Stat5, expression of most male-specific Cyp enzymes was down-regulated showing the sensitivity of this system to Stat5. This study also showed that some of the GH-dependent Cyp enzymes regulation, the so-called type II female genes, depended on continuous GH but were independent of Stat5, suggesting that pathways other than Jak2-Stat5 are involved in their regulation.

\section{Postnatal body growth is dependent on the transcription factors signal transducers and activators of transcription $5 \mathrm{a} / \mathrm{b}$ in muscle: a role for autocrine/paracrine insulin-like growth factor 1}

Klover P, Hennighausen L

Laboratory of Genetics and Physiology, National Institute of Diabetes and Digestive and Kidney Diseases, National

Institutes of Health, Bethesda, Md., USA

kloverp@mail.nih.gov

Endocrinology 2007;148:1489-1497

Background: The transcription factors signal transducers and activators of transcription Stat5a and Stat5b (Stat5) are essential mediators of many actions of GH, including transcription of the IGF1 gene. This study aimed to assess the role of Stat 5 signaling in skeletal muscle.

Methods: Mice with a skeletal-muscle-specific deletion of the Stat5a and Stat5b genes (Stat5MKO mice) were generated using Cre-Lox technology.

Results: IGF1 mRNA levels were reduced by $60 \%$ in muscle tissue of Stat 5 MKO mice. Despite only a $15 \%$ decrease in circulating IGF1, 8 -week-old male Stat 5 MKO mice were approximately $20 \%$ smaller due to a reduction in lean mass. The skeletons of Stat $5 \mathrm{MKO}$ mice were also smaller than controls, indicating the growth defect was not restricted to skeletal muscle.

Conclusion(s): These results demonstrate a critical role for Stat5 in skeletal muscle for local IGF1 production but also for postnatal growth and suggest the skeletal muscle as a major site of $\mathrm{GH}$ action.

In this paper, mice with muscle-specific loss of Stat5 were generated and unexpectedly, these mice displayed reduced longitudinal growth. Growth failure started at 3 weeks of age and was more severe in male compared to female mice, a pattern similar to that seen in defective Stat5 action in mice (but not in humans). Circulating IGF1 levels were reduced by only $15 \%$ and the authors also crossed these Stat5MKO mice with Stat5LKO mice and showed that additional hepatic IGF1 loss did not further affect the growth defect of the former, suggesting that the growth phenotype is not related to reduced circulating IGF1. It is challenging to postulate mechanisms for the effect of muscle-specific loss of Stat5 on skeletal growth. The authors offered the speculation that myocyte-produced IGF1 may affect nearby bone and cartilage cells. Mechanical stimulation of muscle action may also stimulate bone growth (muscular dystrophies are often accompanied with short stature [1]), and is likely reduced in these mice due to their reduced muscle mass. Whether a change in proliferation and maturation of embryonic Myf5 expressing immature myocytes could affect development of the (nearby) chondrocyte pool that develops from the same mesenchymal stem cell population as myocytes, may be another research question. 


\section{Loss of cytokine-Stat5 signaling in the CNS and pituitary gland alters energy balance and leads to obesity}

Lee JY, Muenzberg H, Gavrilova O, Reed JA, Berryman D, Villanueva EC, Louis GW, Leinninger GM, Bertuzzi S, Seeley RJ, Robinson GW, Myers MG, Hennighausen L

Laboratory of Genetics and Physiology, National Institute of Diabetes and Digestive and Kidney Diseases, National Institutes of Health, Bethesda, Md., USA

hennighausen@nih.gov

PLOS ONE 2008;3:e1639

Background: Stat5a and Stat5b (Stat5) are involved in signaling of many cytokines and growth factors and are highly expressed in specific populations of hypothalamic neurons in regions known to mediate the actions of cytokines in the regulation of energy balance. This study aimed to test the hypothesis that Stat5 signaling is essential to energy homeostasis.

Methods: Cre-mediated recombination to delete the Stat5 locus in the CNS was employed, using mice expressing Cre under the Nestin promoter.

Results: Mutant males and females developed severe obesity with hyperphagia, impaired thermal regulation in response to cold, hyperleptinemia and insulin resistance. Furthermore, central administration of GM-CSF mediated the nuclear accumulation of Stat5 in hypothalamic neurons and reduced food intake in control but not in mutant mice.

Conclusion(s): These results demonstrate that Stat5 mediates energy homeostasis in response to endogenous cytokines such as GM-CSF.

The last of this series of papers examined the function of Stat 5 in the hypothalamus. Stat5, and also Stat3, are abundantly present in the hypothalamus and the role of hypothalamic Stat3 in the regulation of energy balance in response to leptin has already been suggested [2]. GH and prolactin activate JAKStat5 signaling in hypothalamic somatostatin and dopaminergic neurons. Nestin-Cre mice were crossed with Stat 5 floxflox mice, resulting in reduced Stat 5 expression throughout the brain (and pituitary). These mice showed late-onset obesity ( $60 \%$ increase in body weight) in both sexes, developing at their adult age of 18-26 weeks, due to a massive increase in fat mass, a slight increase in lean mass, but unchanged length. All peripheral fat pads were enlarged, and adipocyte size rather than number was increased, and, as expected, these mice displayed insulin resistance. These mice had increased food intake, reduced energy expenditure, and reduced ability to maintain normal body temperature, showing some resemblance to rats overexpressing hGH globally [3]. Interestingly, the arcuate nucleus showed normal NPY, AgRP and POMC expression, but reduced expression of the Stat5 target gene SOCS3. SOCS3 is involved in feedback regulation of Stat signaling but SOCS3 deficiency results in enhanced leptin sensitivity and resistance to diet induced obesity [4]. However, the authors show that the lack of action of GM-CSF is at least partly responsible for the phenotype of these brain Stat5 null mice - a reminder that Stat5 is a signaling molecule for a wide spectrum of cytokines other than $\mathrm{GH}$. Whether other endocrine activators of Stat5 also play a role in all three tissues remains to be established.

\section{New genes, or old genes in a different wrapping}

\section{Gain-of-function RAF1 mutations cause Noonan and LEOPARD syndromes with hypertrophic cardiomyopathy}

Pandit B, Sarkozy A, Pennacchio LA, Carta C, Oishi K, Martinelli S, Pogna EA, Schackwitz W, Ustaszewska A, Landstrom A, Bos JM, Ommen SR, Esposito G, Lepri F, Faul C, Mundel P, Lopez Siguero JP, Tenconi R, Selicorni A, Rossi C, Mazzanti L, Torrente I, Marino B, Digilio MC, Zampino G, Ackerman MJ, Dallapiccola B, Tartaglia M, Gelb BD Center for Molecular Cardiology, Department of Pediatrics and Department of Genetics and Genomic Sciences, Mount Sinai School of Medicine, New York, N.Y., USA

Mtartaglia@iss.it, bruce.gelb@mssm.edu

Nat Genet 2007;39:1007-1012

Background: Noonan and LEOPARD syndromes are developmental disorders with common features such as cardiac abnormalities, short stature and facial abnormalities. Increased RAS signaling due to 
PTPN11, SOS1 and KRAS mutations is identified in approximately $60 \%$ of Noonan syndrome cases, and PTPN11 mutations are identified in approximately $90 \%$ of LEOPARD syndrome cases.

Methods: Mutational analysis of RAF1, which encodes a serine-threonine kinase that activates MEK1 and MEK2, was performed in patients with Noonan syndrome without PTPN11 or SOS1 mutations $(\mathrm{n}=148)$ and 6 patients with LEOPARD syndrome without PTPN11 mutations.

Results: Missense mutations in RAF1 were found as a cause for Noonan syndrome in 18 out of a total of 231 patients and 2 of 6 patients with LEOPARD syndrome. Most mutations altered a motif flanking Ser259, a residue critical for autoinhibition of RAF1. Of 19 subjects with a RAF1 mutation in two hotspots, 18 showed hypertrophic cardiomyopathy (HCM), compared with the $18 \%$ prevalence of HCM among individuals with Noonan syndrome in general. RAF1 mutants from the two HCM hotspots had increased kinase activity and enhanced ERK activation, whereas the mutations that were non-HCM-associated were kinase-impaired.

Conclusion(s): These findings further implicate increased RAS signaling in pathological cardiomyocyte hypertrophy.

\section{Germline gain-of-function mutations in RAF1 cause Noonan syndrome}

Razzaque MA, Nishizawa T, Komoike Y, Yagi H, Furutani M, Amo R, Kamisago M, Momma K, Katayama H, Nakagawa M, Fujiwara Y, Matsushima M, Mizuno K, Tokuyama M, Hirota H, Muneuchi J, Higashinakagawa T, Matsuoka R

International Research and Educational Institute for Integrated Medical Sciences (IREIIMS), Tokyo Women's Medical University, Tokyo, Japan

rumiko@imcir.twmu.ac.jp

Nat Genet 2007;39:1013-1017

Background: Noonan syndrome is characterized by short stature, facial dysmorphia and a wide spectrum of congenital heart defects. Mutations in PTPN11, KRAS and SOS1 are responsible for approximately $60 \%$ of cases of Noonan syndrome but the gene(s) responsible for the remainder are unknown.

Methods: Mutational analysis of RAF1 was performed and in addition, zebrafish were used to study embryonic Raf1 expression and effects of down-regulation of Raf1.

Results: Five different mutations in RAF1 were identified in 10 individuals with Noonan syndrome. Patients carrying mutations causing changes in the CR2 domain of RAF1 had hypertrophic cardiomyopathy (HCM), whereas affected individuals with mutations leading to changes in the CR3 domain did not.

Conclusion(s): These findings implicate RAF1 gain-of-function mutations as causative of a human developmental disorder, representing a new genetic mechanism for the activation of the RAS-MAPK pathway.

In Yearbook 2007 [5], we discussed the discovery of mutations in PTPN11, SOS1 and KRAS in patients with Noonan syndrome, and described the mechanism leading to this condition, namely increased activity of the MAPK-ERK pathway. Activating mutations in PTPN11, also called SHP2, are a cause of approximately $50 \%$ of Noonan syndrome. PTPN11 is involved in GH signaling and normally binds to GHR and inhibits JAK-Stat signaling, and thus patients with Noonan syndrome carrying PTPN11 mutations have a mild degree of $\mathrm{GH}$ insensitivity and respond less well to $\mathrm{GH}$ treatment than other patients with the syndrome. Noonan patients with PTPN11 mutations are also more likely to manifest pulmonic stenosis and less likely to have hypertrophic cardiomyopathy. The papers above are important for a few reasons. They show very clearly that mutations in RAF1, which was initially discovered as a mitogenic factor and a cooperating factor for BCL-2 to suppress apoptosis [6], are yet another cause for Noonan syndrome. The RAF1 mutations result in constitutive activation and, like gain-offunction mutations in PTPN11, SOS1 and KRAS in Noonan syndrome, activate MAPK-ERK signaling. But despite the similarity in the mechanism with overactivation of MAPK-ERK signaling, $95 \%$ of patients that carry RAF1 mutations have hypertrophic cardiomyopathy, whereas patients with mutations in PTPN11 are more likely to suffer from pulmonic stenosis. The authors therefore then went on to study roles of PTPN11 and Raf1 in development and found differential expression patterns for the 2 genes in zebrafish development. They also 'knocked down' gene expression for PTPN11 and Raf1 in zebrafish, and although in the context of Noonan syndrome, overexpression of PTPN11 or Raf1 would be more relevant, the authors were able to show that these 2 genes have differential effects on cardiac morphology. Two more observations should be highlighted. First, RAF1 mutations that do 
not affect the autoinhibition of RAF1 are not associated with HCM. Secondly, LEOPARD syndrome (an acronym for multiple Lentigines, ECG conduction abnormalities, Ocular hypertelorism, Pulmonic stenosis, Abnormal genitalia, Retardation of growth, sensorineural Deafness), which is on the opposite end of the spectrum of Noonan syndrome, is caused by inactivating mutations of PTPN11; however, like in Noonan syndrome, activating mutations in RAF1 cause HCM in these patients. Apart from implying that increased RAF1-MAPK-ERK signaling may lead to hypertrophic cardiomyopathy, these studies emphasize that dissection of genetic causes of these syndromes can reveal distinct genotypephenotype relationships that help in the clinical management. It may be time to depart from the term Noonan syndrome, and use mechanistic nomenclature for these different syndromes that are based on mutations in different genes.

\title{
Mutations in RNF135, a gene within the NF1 microdeletion region, cause phenotypic abnormalities including overgrowth
}

\author{
Douglas J, Cilliers D, Coleman K, Tatton-Brown K, Barker K, Bernhard B, Burn J, Uson S, Josifova D, Lacombe D, \\ Malik M, Mansour S, Reid E, Cormier-Daire V, Cole T, The Childhood Overgrowth Collaboration, Rahman N \\ Section of Cancer Genetics, Institute of Cancer Research, Sutton, UK \\ nazneen.rahman@icr.ac.uk
}

Nat Genet 2007;39:963-965

Background: Neurofibromatosis type 1 (NF1), with an incidence of 1 in 3,000, can be due to intragenic mutations in the NF1 gene in approximately 905 of cases. Of the remaining cases, $5-10 \%$ are due to $17 \mathrm{q} 11$ microdeletions that encompass NF1. The most common (type 1$)$ deletion $(1.4 \mathrm{Mb})$ contains 13 genes in addition to NF1, and is usually generated by non-allelic homologous recombination between flanking low-copy repeats known as NF1REPa and NF1REPc. The phenotype of NF1 associated with 17q11 microdeletions differs from that associated with intragenic NF1 mutations, and includes facial dysmorphism, learning difficulties, congenital heart defects, high numbers of neurofibromas and tall stature. The authors hypothesized that haploinsufficiency of a gene within the $17 \mathrm{q} 11$ microdeletion might promote human growth.

Methods: A cohort of patients with overgrowth in childhood (height and head circumference at least +2 SDS), in association with some degree of learning difficulty, were screened for mutations in 12 of the 14 genes that are deleted in type 1 microdeletion, using conformation-sensitive gel electrophoresis (CSGE) and bidirectional sequencing of genomic DNA. The recognizable overgrowth conditions such as Sotos syndrome, Bannayan-Riley-Ruvalcaba syndrome, Simpson-Golabi-Behmel syndrome and Beckwith-Wiedemann syndrome were excluded molecularly or clinically.

Results: Mutations were not identified in 11 of 12 genes. However, truncating mutations were identified in RNF135 in 4 out of 245 unrelated individuals with overgrowth phenotypes. A microdeletion that encompasses RNF135 and 4 other genes located between low-copy repeats known as NF1REPa and NF1REPc was also identified in a further individual with overgrowth. No truncating mutations $(0 / 510)$, nor any microdeletions (0/192), were identified in normal individuals. A heterozygous missense mutation $(\mathrm{R} 286 \mathrm{H})$ was identified in a further individual with a phenotype that was similar to that of the individuals with a truncating mutation. All the individuals with genetic changes in RNF135 had dysmorphic facial features that were similar to those individuals with NF1 microdeletions. The overgrowth was global, postnatal in onset, and mild-moderate in degree. All the mutations were inherited, and tall stature seemed to normalize towards adulthood. RNF135 is widely expressed and encodes a protein of 432 amino acids; it contains a RING finger domain at the N-terminus, and a B30.2/SPRY domain at the C-terminus.

Conclusion(s): Intragenic RNF135 mutations are associated with a condition characterized by overgrowth, dysmorphism, and variable additional features including learning disability.

This paper reports heterozygous mutations in RNF135 in 4 of 245 unrelated individuals with an overgrowth syndrome characterized by increased postnatal height and weight, macrocephaly, variable learning disability, and dysmorphic facial features. Although none had clinical features of NF1, the facial features were similar to the NF1 deletion syndrome including broad forehead, downslanting palpebral fissures, broad nasal tip, long philtrum, and thin upper lip. Variable features in one or two patients included deafness, optic nerve hypoplasia, advanced bone age, ataxia, autistic features, and pulmonary stenosis. These data implicate RNF135 in the growth processes, and haploinsufficiency appears to be associated with overgrowth phenotypes. 


\section{Mutations in pericentrin cause Seckel syndrome with defective ATR-dependent DNA damage signaling}

Griffith E, Walker S, Martin C, Vagnarelli P, Stiff T, Vernay B, Al Sanna N, Saggar A, Hamel B, Earnshaw WC, Jeggo

PA, Jackson AP, O'Driscoll M

MRC Human Genetics Unit, Western General Hospital, Edinburgh, UK

andrew.jackson@hgu.mrc.ac.uk

Nat Genet 2008;40:232-236

Background: Seckel syndrome is an autosomal recessive disorder characterized by intrauterine growth retardation, severe proportionate stature and marked microcephaly. Mutations in the ataxia-telangiectasia and Rad3-related $(A T R)$ gene have been identified in some individuals with Seckel syndrome (ATR-Seckel). The gene encodes a phosphatidylinositol-3-kinase-like kinase that has distinct but overlapping functions with ATM in coordinating the response to DNA damage. Cell lines of individuals with Seckel syndrome who do not have a mutation in ATR also show ATR-pathway dysfunction, suggesting that mutation of additional genes encoding proteins involved in this DNA damage response cascade may also be implicated in the etiology of this disorder. Additionally, the ATR DNA damage response pathway has also been implicated in some cases of microcephaly.

Methods: The authors performed a SNP-microarray genome-wide homozygosity scan on two consanguineous Middle-Eastern families that included individuals clinically diagnosed with Seckel syndrome, with cellular evidence of defective ATR signaling. They identified a new locus Sckl4 containing 55 annotated genes including pericentrin $(P C N T)$, a gene that encodes a centrosomal protein. The latter appeared to be a good candidate, and its 47 coding exons were sequenced in affected individuals.

Results: A homozygous nonsense mutation was identified in exon 4 of family 1 (E220X), and a homozygous single-base pair deletion leading to frameshift was identified in exon 12 in family 2 (S629fs). A homozygous single-base pair insertion was identified in a further individual, resulting in a frameshift. Pericentrin is a large coiled coil protein with a C-terminal PACT domain that targets it to the centrosome. Pericentrin localizes to the pericentriolar material (PCM), where it interacts with several structural centrosomal proteins, and plays an important role in microtubular nucleation and spindle organization. Antibodies to pericentrin disrupt mitosis, and the protein also acts as a scaffold to recruit signaling proteins such as protein kinase A to the centrosome. Pericentrin staining was lost in mutant lymphoblastoid cell lines, and the mutations led to defects in ATR-dependent checkpoint signaling. Conclusion(s): Mutations in pericentrin (PCNT) were identified in a cohort of patients with Seckel syndrome, and led to defective ATR-dependent DNA damage signaling. These data suggest that other known microcephaly genes implicated in either DNA repair responses or centrosomal function may act in common developmental pathways determining human brain and body size.

\section{Mutations in the Pericentrin (PCNT) Gene Cause Primordial Dwarfism}

Rauch A, Thiel CT, Schindler D, Wick U, Crow YJ, Ekici AB, van Essen AJ, Goecke TO, Al-Gazali L, Chrzanowska KH, Zweier C, Brunner HG, Becker K, Curry CJ, Dallapiccola B, Devriendt K, Dörfler A, Kinning E, Megarbane A, Meinecke P, Semple RK, Spranger S, Toutain A, Trembath RC, Voss E, Wilson L, Hennekam R, de Zegher F, Dörr HG, Reis A Institute of Human Genetics, University Hospital Erlangen, Erlangen, Germany

Anita.Rauch@humgenet.uni-erlangen.de

Science 2008;319:816-819

Background: Microcephalic osteodysplastic primordial dwarfism type Majewski II (MOPD II) is an autosomal recessive disorder characterized by extreme pre- and postnatal growth retardation, bone and dental anomalies, far-sightedness, irregular pigmentation, truncal obesity, type 2 diabetes in older individuals, reduced life expectancy due to cerebral vascular anomalies, and grossly normal brain development in spite of a severely reduced brain size. Genome-wide linkage analysis using polymorphic short tandem repeat markers revealed a single disease locus on chromosome 21q22.3, and this 4.6-Mb region contained a likely candidate gene, Pericentrin (PCNT, see above).

Methods: Mutational analysis of the 47 exons of PCNT was performed in 25 unrelated patients with MOPD II.

Results: Mutational screening revealed homozygous and compound heterozygous null mutations in PCNT in all individuals. Heterozygous individuals were phenotypically normal. It is likely that pericentrin-depleted human cells are more susceptible to death because of defective mitosis and chromosome 
segregation. This would result in a decrease in total cellularity of the embryo and growth restriction in the adult. In accordance with this hypothesis, Rauch et al. observed abnormal mitotic morphology in $71 \%$ of MOPD II fibroblast cells, together with low-level mosaic variegated aneuploidy (MVA) and premature sister chromatid separation (PCS). These findings indicate an additional role of PCNT in the spindle assembly checkpoint, in the absence of which cells do not arrest in metaphase but prematurely separate sister chromatids and then exit mitosis.

Conclusion(s): Recessive loss-of-function mutations in Pericentrin are associated with MOPDII.

These two papers describe recessive mutations in a novel gene, Pericentrin (PCNT), that are associated with two different phenotypes, namely Seckel syndrome and microcephalic osteodysplastic primordial dwarfism type Majewski II (MOPD II). The importance of these papers lies in the association between mutations in a gene that is implicated in basic processes such as mitosis and DNA repair and growth. The effects of mutations are profound, although the phenotypic variability remains unexplained. It is likely that other genes implicated in basic cellular processes may also be implicated in growth. The localization of this gene on chromosome 21 raises a question about the possible effect of triploid expression in Down syndrome.

\section{A common variant of HMGA2 is associated with adult and childhood height in the general population}

Weedon MN, Lettre G, Freathy RM, Lindgren CM, Voight BF, Perry JRB, Elliott KS, Hackett R, Guiducci C, Shields B, Zeggini E, Lango H, Lyssenko V, Timpson NJ, Burtt NP, Rayner NW, Saxena R, Ardlie K, Tobias JH, Ness AR, Ring SR, Palmer CNA, Morris AD, Peltonen L, Salomaa V, The Diabetes Genetics Initiative, The Wellcome Trust Case Control Consortium, Smith GD, Groop L, Hattersley AT, McCarthy MI, Hirschhorn JN, Frayling TM

Genetics of Complex Traits/Diabetes Genetics, Institute of Biomedical and Clinical Science, Peninsula Medical School, Exeter, UK

Nat Genet 2008;39:1245-1250

Background: Human height is a classic, highly heritable, quantitative, polygenic trait. Twin, family and adoption studies suggest that up to $90 \%$ of normal variation in human height within populations is due to genetic variation. Several genetic mutations have been implicated in the etiology of rare syndromes with extreme stature, and many regions of the genome have been linked with height based on numerous genome-wide linkage scans, but until recently, there have not been any examples of gene variants that are reproducibly associated with height variation in the general population.

Methods: Genome-wide association (GWA) data have been studied from 4,921 individuals. The population consisted of 1,896 UK individuals with type 2 diabetes mellitus from the Wellcome Trust Case Control Consortium (WTCCC) and 3.025 Swedish or Finnish participants (1,496 individuals with type 2 diabetes and 1,529 non-diabetic controls from the Diabetes Genetics Initiative (DGI)). All participants were of self-reported European ancestry. All DNA samples were genotyped using the Affymetrix GeneChip Human Mapping 500K platform. Meta-analysis of sex- and age-adjusted height Z scores was performed for the 364,301 autosomal SNPs common across the data sets.

Results: Two SNPs were most strongly associated with height in the meta-analysis, namely rs 1042725 and rs7968682, both in linkage disequilibrium with each other, and the only SNPs to reach a level of statistical significance strongly suggestive of true association. The two SNPs lie in (rs1042725) and $12 \mathrm{~kb}$ downstream (rs7968682) of the 3'-UTR region of the high mobility group-A2 (HMGA2) gene, a strong biological candidate for influencing height, as rare severe mutations in this gene alter body size in mice and humans. The association was confirmed in 19,064 adults from four further studies. The association was also observed in children and a tall/short case/control study. It has been estimated that rs1042725 explains approximately $0.3 \%$ of population variation in height $(\sim 0.4 \mathrm{~cm}$ increased adult height per C allele).

Conclusion(s): These studies represent the first consistently replicated association with adult and childhood height, and the SNP in HMGA2 explains approximately $0.3 \%$ of the variation in height. 


\section{Common variants in the GDF5-UQCC region are associated with variation in human height}

Sanna S, Jackson AU, Nagaraja R, Willer CJ, Chen WM, Bonnycastle LL, Shen H, Timpson N, Lettre G, Usala G, Chines PS, Stringham HM, Scott LJ, Dei M, Lai S, Albai G, Crisponi L, Naitza S, Doheny KF, Pugh EW, Ben-Shlomo Y, Ebrahim S, Lawlor DA, Bergman RN, Watanabe RM, Uda M, Tuomilehto J, Coresh J, Hirschhorn JN, Shuldiner AR, Schlessinger D, Collins FS, Smith GD, Boerwinkle E, Cao A, Boehnke M, Abecasis1 GR, Mohlke KL Center for Statistical Genetics, Department of Biostatistics, University of Michigan, Ann Arbor, Mich., USA goncalo@umich.edu

Nat Genet 2008;40:198-203

Background: Height is a complex trait that is determined by both genetic and environmental factors, including diet and the prenatal environment. Rare mutations with large effects on height in mendelian syndromes have been identified in the genes FBN1, FGFR3, GH1, EVC, EVC2, and GPC3. Common variants in the HMGA2 gene are associated with variation in height in the general population [see Weedon et al., 2008].

Methods: Genome-wide SNP data were analyzed on 2,371 Finns from the Finland-United States Investigation of NIDDM Genetics (FUSION) study, and on 4,298 Sardinians from the SardiNIA study, a longitudinal study on aging-related conditions in Sardinia. Genotyped and imputed markers were used to evaluate the association between height and $\sim 2.28$ million common genetic variants. The overall accuracy of imputed genotypes was verified in a few markers, and thereafter the authors conducted within-study analyses with a rapid variance components-based association test followed by a metaanalysis of the two studies.

Results: The data confirmed the association between height and two common variants in HMGA2. The strongest signal was obtained with a genetic locus on chromosome 20, where 2 genes could be postulated to play a role in growth. This region overlaps a locus associated with osteoarthritis susceptibility. Rare variants in growth differentiation factor 5 (GDF5) have been associated with disorders of skeletal development whilst UQCC encodes a ZIC-binding protein repressed by basic fibroblast growth factor (FGF). The SNP that was most significantly associated with height in the meta-analysis of imputed HapMap SNPs was rs725908, which is in strong linkage disequilibrium (LD) with rs6060369. The latter mark was originally imputed in the FUSION GWAS, but direct genotyping confirmed the association. Each copy of the $\mathrm{C}$ allele at rs6060369 was associated with an increase in height of $0.3-0.7 \mathrm{~cm}$, accounting for $0.3-0.6 \%$ of the variance in height, after adjustment for age and gender. The association was confirmed in nine follow-up samples comprising 23,684 individuals of European ancestry and 3,860 African-American individuals $(0.2-0.6 \mathrm{~cm}$ increment in height, $0.3-0.5 \%$ of the variance in height). The association was confirmed in the 1958 British Birth Cohort. UQCC is present in differentiating chondrocytes, and is first expressed at early stages of mesenchymal cell proliferation. It is downregulated by the addition of FGF2 in mouse embryonic stem cells. GDF5 is a member of the transforming growth factor- $\beta$ superfamily and is involved in bone growth and differentiation in both adult and embryonic tissues. It is expressed in the primordial cartilage of long bones and GDF5 mutations are associated with several disorders of skeletal development. A SNP located in the 5'-UTR of GDF5, rs143383, is strongly associated with osteoarthritis, and is in strong LD with rs6060369 in the HapMap, FUSION, and SardiNIA samples. Analysis of this SNP in the screening samples revealed that the rs143383 A allele, which was previously associated with increased risk of osteoarthritis, was associated with a decrease in height, and this association was more marked than that of rs6060369 in the ARIC African-American samples. The A allele of rs143383 is associated with decreased transcriptional activity of GDF5 in chondrogenic cells, and this could in turn lead to reduction in limb bone growth and height.

Conclusion(s): Common variants in the osteoarthritis-associated locus GDF5-UQCC contribute to variation in height with an estimated additive effect of $0.44 \mathrm{~cm}$, and these data suggest a link between the genetic basis of height and osteoarthritis, potentially mediated through alterations in bone growth and development. 


\section{Genome-wide association analysis identifies $\mathbf{2 0}$ loci that influence adult height}

Weedon MN, Lango H, Lindgren CM, Wallace C, Evans DM, Mangino M, Freathy RM, Perry JRB, Stevens S, Hall AS, Samani NJ, Shields B, Prokopenko I, Farrall M, Dominiczak A, Diabetes Genetics Initiative, The Wellcome Trust Case Control Consortium, Johnson T, Bergmann S, Beckmann JS, Vollenweider P, Waterworth DM, Mooser V, Palmer CNA, Morris AD, Ouwehand WH, Cambridge GEM Consortium22, Caulfield M, Munroe PB, Hattersley AT, McCarthy $\mathrm{MI}$, Frayling TM

Genetics of Complex Traits/Diabetes Genetics, Institute of Biomedical and Clinical Science, Peninsula Medical School, Exeter, UK

Nat Genet 2008;40:575-583

Background: Adult height, a polygenic trait, forms the ideal phenotype for genetic studies of quantitative traits in humans, as it is easily and accurately measured and highly heritable, with up to $90 \%$ of variation in adult height within a population being explained by genetic variation.

Methods: GWA data from five studies that ranged in size from 1,437 to 3,560 people of European ancestry from the UK and a sixth study of 2,978 Scandinavian individuals for whom summary height association statistics have been made publicly available were used. All studies were genotyped using the Affymetrix $500 \mathrm{~K}$ chip. A total of 39 SNPs were then taken forward into the second stage of the study, which involved genotyping of an additional 16,482 individuals of European ancestry from four studies. Results: In the stage 2 analysis, 20 of the 39 SNPs reached a $p<0.005$, with the same direction of effect as the GWA data; all of these reached a $\mathrm{p}<5 \times 10^{-7}$ in a joint analysis across GWA and stage 2 samples. Of the 20 loci implicated in these studies, at least 10 have been implicated in the regulation of growth, because of known effects from mouse knockouts or human syndromes. These include genes that implicate a number of biological pathways and processes in the normal determination of human height, including the Hedgehog signaling pathway (IHH, HHIP, PTCH1), basic cell cycle regulation (CDK6), extracellular matrix (ADAMTSL3 and EFEMP1), and chromatin rearrangement and polycomb proteins (HMGA2 and SCMH1). Additionally, the association with GDF5 (see above) was also confirmed in this study. Several of the genes are also disrupted in cancers, e.g. HMGA2, CDK6 and DLEU7. The effects on height were not different in those aged $>50$ years from those $<50$ years, suggesting that the effects are predominantly on development and childhood growth, as opposed to loss of height. Analysis of the UK stage 2 samples revealed that the 20 SNPs explain $\sim 2.9 \%$ of the variance in adult height in the sample. There was a $0.7 \mathrm{SD}(\sim 5 \mathrm{~cm})$ difference in height between the $6.2 \%$ of people with 17 or fewer 'tall' alleles compared to the $5.5 \%$ of people with 27 or more.

Conclusion(s): The data suggest that many variants of individually small effect explain the heritability of height. The 20 robustly associated variants alter height by between $\sim 0.2$ and $0.6 \mathrm{~cm}$ per allele, and they explain only $\sim 3 \%$ of the variation in height within the population. The loci identified implicate genes in the Hedgehog signaling, extracellular matrix and cancer pathways, and provide novel insights into human growth and developmental processes, and into the genetic architecture of a classic quantitative trait.

These 3 studies together with 2 others $[7,8]$ open new avenues in our understanding of growth. Human height lends itself to genome-wide association (GWA) studies as it is a highly heritable, quantitative and measurable trait. It takes thousands of subjects with detailed phenotype to run a GWA study. To date, a number of loci have been associated with stature, yet, together these account for a mere $2.9 \%$ of the variance in adult height. The genes implicate a number of biological pathways and processes in the normal determination of human height, each contributing its minute impact, including the Hedgehog signaling pathway, basic cell cycle regulation, extracellular matrix, and chromatin rearrangement and polycomb proteins.

Gudbjartsson et al. [8] identified 27 loci in data derived from seven different populations. The association with HMGA2 was confirmed, but the most significant association was with variants in the ZBTB38 (zinc finger and BTB domain containing 38) gene on 3q23, which encodes a protein that has been shown to repress transcription by specifically binding to methylated DNA. The rat homologue of the gene, Zenon, regulates transcription of the tyrosine hydroxylase gene, the rate-limiting enzyme of catecholamine biosynthesis. A significant excess of markers was close to genes implicated in skeletal development (BMP2, BMP6, EFEMP1, FBLN5 and NOG). A significant association was observed between SNPs in the ADAMTS17 and height. SNPs in ADAMTS10 showed a suggestive association with height, whilst SNPs in ADAMTS3 were associated with height when the AfricanAmerican samples were excluded. Members of the ADAMTS (a disintegrin-like and metalloproteinase with thrombospondin) family encode enzymes that mediate cartilage aggrecan loss. Many of the loci 
associated with genes implicated in cell cycle regulation (HMGA1, HMGA2, NCAPG, CDK6 and COIL). Loci identified in this manuscript explain around $3.7 \%$ of the height diversity in the population.

The study by Lettre et al. [7] performed a meta-analysis of six GWA datasets which included height association results for 15,821 individuals at $\sim 2.2$ million SNPs to detect additional loci associated with height. They identified ten new associations between common SNPs and height variation, and an additional four associations with strongly suggestive evidence, in addition to confirming two previously reported associations (HMGA2 and GDF5-UQCC). The newly identified loci associated with height implicate several biological pathways or gene sets, including targets of the let-7 microRNA (HMGA2, the cell cycle regulator $C D K 6$, the histone methyltransferase $D O T 1 L$, and the gene LIN28B), chromatin remodeling proteins and Hedgehog signaling (HHIP). The association with ZBTB38 was also confirmed [8]. It is clear that human height is a polygenic trait and that many genes implicated in growth remain to be identified. It is likely that each variant will make only a small contribution to phenotypic variation, and in some cases, implicated SNPs may be but neighbors of growth-related genes. However, it is also likely that these genes will be good candidates for as yet unexplained syndromes of severe tall or short stature.

\section{$11 p 15$ imprinting center region 1 loss of methylation is a common and specific cause of typical Russell-Silver syndrome: clinical scoring system and epigenetic-phenotypic correlations}

Netchine I, Rossignol S, Dufourg MN, Azzi S, Rousseau A, Perin L, Houang M, Steunou V, Esteva B, Thibaud N, Demay MC, Danton F, Petriczko E, Bertrand AM, Heinrichs C, Carel J-C, Loeuille GA, Pinto G, Jacquemont ML, Gicquel C, Cabrol S, Le Bouc Y

Hôpital Armand-Trousseau, Explorations Fonctionnelles Endocriniennes, Paris, France

irene.netchine@trs.aphp.fr

J Clin Endocrinol Metab 2007;92:3148-3154

Background: Maternal uniparental disomy for chromosome 7 (mUPD7) is found in $5-10 \%$ of patients with Russell-Silver syndrome (RSS). Recently, loss of methylation (LOM) of 11p15 [Imprinting Center Region 1 (ICR1) domain] has been identified as a further mechanism leading to RSS. The aim of this study was to screen for 11p15 epimutations and mUPD7 in RSS and non-RSS small-for-gestational-age (SGA) patients in order to identify epigenetic-phenotypic correlations.

Methods: 127 SGA patients were analyzed. Clinical diagnosis of RSS was established when SGA was associated with at least three of five criteria: postnatal growth retardation, relative macrocephaly, prominent forehead, body asymmetry, and feeding difficulties.

Results: Of the 127 SGA patients, 58 were diagnosed with RSS; 37 of these $(63.8 \%)$ displayed partial LOM of the 11p15 ICR1 domain, and $3(5.2 \%)$ had mUPD7. No molecular abnormalities were found in the non-RSS SGA group $(\mathrm{n}=69)$. Birth weight, birth length, and postnatal body mass index (BMI) were lower in the abnormal 11p15 RSS group (ab-ICR1-RSS) compared with the normal 11p15 RSS group ( -3.4 vs. $-2.6 \mathrm{SD}$ score (SDS), -4.4 vs. $-3.4 \mathrm{SDS}$, and -2.5 vs. $-1.6 \mathrm{SDS}$, respectively; $\mathrm{p}<0.05$ ). Among RSS patients, prominent forehead, relative macrocephaly, body asymmetry, and low BMI were significantly associated with ICR1 LOM. All ab-ICR1-RSS patients had at least four of five criteria of the scoring system.

Conclusion(s): The 11p15 ICR1 epimutation is a major, specific cause of RSS exhibiting failure to thrive. The authors propose a clinical scoring system (including a BMI $<-2$ SDS), highly predictive of $11 \mathrm{p} 15$ ICR1 LOM, for the diagnosis of RSS.

This paper is similar to the above papers in that it tries to define genotype-phenotype correlations, or in the case of RSS due to abnormalities of imprinting - epigenotype-phenotype relations. The authors found that loss of methylation (LOM) in $11 \mathrm{p} 15$ was identified in $64 \%$ of patients that were diagnosed as having RSS with the scoring system that they developed (based on postnatal growth retardation, relative macrocephaly, prominent forehead, body asymmetry, and feeding difficulties) and that prominent forehead, relative macrocephaly, body asymmetry, and low BMI were significantly associated with ICR1 LOM. In another study by Binder et al., it was subsequently shown that those patients with LOM of $11 \mathrm{p} 15$, but not other causes of RSS or SGA, showed increased IGF1 and IGFBP3 concentrations, suggesting that there may be counterregulation by IGF1 or resistance to some actions of IGF1 [9]. 


\title{
Inactivation of the mouse Mage/2 gene results in growth abnormalities similar to Prader-Willi syndrome
}

\author{
Bischof JM, Stewart CL, Wevrick R \\ Department of Medical Genetics, University of Alberta, Edmonton, Alta., Canada \\ Rachel.wevrick@ualberta.ca
}

Hum Mol Genet 2007;16:2713-2719

\begin{abstract}
Background: Prader-Willi syndrome (PWS) is an imprinted genetic obesity disorder characterized by abnormalities of growth and metabolism. It is a contiguous gene deletion disorder caused by loss of imprinted genes on chr 15q11-q13. Clinical features include neonatal hypotonia, failure to thrive, low metabolic rate, disordered sleep, growth hormone deficiency, childhood-onset severe obesity, hypogonadotrophic hypogonadism, and developmental delay. Mouse strains with loss of function of one or more of the PWS genes do not recapitulate the PWS obesity phenotype. MAGEL2 and necdin are related proteins that are both inactivated in PWS. Mice with a targeted deletion of Magel2 have a circadian rhythm defect. They have significantly reduced levels of the neuropeptide hormones orexin A/B and fewer neurons expressing orexin in the lateral hypothalamus. Whether Magel2 is implicated in the hypothalamic dysfunction associated with Prader-Willi syndrome remains to be established.

Methods: Magel2 was inactivated using gene targeting to replace the open reading framewidth an in frame LacZ knock-in expression cassette, then back-crossing to $\mathrm{C} 57 \mathrm{Bl} / 6$. Expression of Magel2 was ablated in all tissues of the Magel2 null mice because of deletion of the paternal allele of Magel 2 and imprinting that silences the maternal allele.

Results: Magel2 null mice were underrepresented among embryos and pups, suggesting an early embryonic lethal event in a subset of Magel2 null embryos. Although there was no difference in birth weight between mutant and wild-type mice, postnatal growth retardation was evident between P7 and weaning between P21 and P28. Postweaning, the mutant mice exhibited catch-up growth followed by excessive weight gain. The percentage lean mass was reduced with an increase in fat mass. Fasting insulin and cholesterol concentrations were increased.

Conclusion(s): Magel2 null mice exhibit neonatal growth retardation, excessive weight gain after weaning, and increased adiposity with altered metabolism in adulthood, recapitulating fundamental aspects of the PWS phenotype.
\end{abstract}

\begin{abstract}
The exact contribution made by individual genes located at chr 15q11-q13 to the PWS phenotype remains unknown. This work reports that inactivation of Magel2 in the mouse can recapitulate the growth and obesity phenotype in this condition. However, a proportion of PWS patients manifest GH deficiency, and it is unclear whether Magel2 is associated with this. Magel2 is a protease inhibitor of Fez1, which is implicated in axonal outgrowth and kinesin-mediated transport. The catch-up growth that the Magel2 null mice demonstrate suggests that other genes may be implicated in the growth phenotype.
\end{abstract}

\section{New mechanisms}

\section{Growth hormone enhances thymic function in HIV-1-infected adults}

Napolitano LA, Schmidt D, Gotway MB, Ameli N, Filbert EL, Ng MM, Clor JL, Epling L, Sinclair E, Baum PD, Li K, Killian ML, Bacchetti P, McCune JM

Gladstone Institute of Virology and Immunology, San Francisco, Calif., USA

Inapolitano@gladstone.ucsf.edu

J Clin Invest 2008;118:1085-1098

Background: Growth hormone $(\mathrm{GH})$ has been reported to regulate T-cell development and to reverse agerelated declines in thymopoiesis in rodents.

Methods: A prospective randomized open-label crossover study examined the effects of daily GH treatment on the immune system of $22 \mathrm{HIV}-1$-infected adults on antiretroviral treatment.

Results: GH treatment was associated with increased thymic mass. In addition, GH treatment enhanced thymic output, as measured by both the frequency of T-cell receptor rearrangement excision circles in circulating $\mathrm{T}$ cells and the numbers of circulating naive and total CD4+ T cells. 
Conclusion(s): These findings provide evidence that $\mathrm{GH}$ induces de novo T-cell production and may facilitate CD4+ T-cell recovery in HIV-1-infected adults. The data also suggest that thymic involution can be pharmacologically reversed in humans.

\section{Non-redundant roles for Stat5a/b in directly regulating Foxp3}

Yao Z, Kanno Y, Kerenyi M, Stephens G, Durant L, Watford WT, Laurence A, Robinson GW, Shevach EM, Moriggl R, Hennighausen L, Wu C, O'Shea JJ

Molecular Immunology and Inflammation Branch, National Institute of Arthritis and Musculoskeletal and Skin

Diseases, National Institutes of Health, Bethesda, Md., USA

Blood 2007; 109:4368-4375

Background: Stats (signal transducers and activators of transcription) regulate multiple aspects of T-cell fate. T-regulatory (Treg) cells are a critical subset that limits immune responses, but the relative importance of Stat $5 \mathrm{a} / \mathrm{b}$ versus Stat 3 for Treg cell development has been contentious. This study examined the role of Stat5 in T-cell development.

Methods and Results: The authors observed that peripheral CD25+CD4+ T cells were reduced in Stat $5(\delta \mathrm{N})$ mice; however, the levels of Foxp3, a transcription factor that is critical for Treg cells, were normal. In contrast, complete deletion of Stat $5 \mathrm{a} / \mathrm{b}\left[\mathrm{Stat}^{-1-}\right]$ resulted in dramatic reduction in CD25- or Foxp3expressing CD4+ T cells. An intrinsic requirement was demonstrated by reduction of Stat5a/b in CD4-expressing cells and by stem cell transplantation using Stat $5^{-1-}$ fetal liver cells. Stat5a/b were also required for optimal induction of Foxp3 in vitro and bound directly to the Foxp3 gene. Reduction of Stat 3 in T cells did not reduce the numbers of Treg cells in the thymus or spleen; however, Stat 3 was required for IL-6-dependent down-regulation of Foxp3.

Conclusion(s): Stat $5 \mathrm{a} / \mathrm{b}$ have an essential, non-redundant role in regulating Treg cells, and Stat 3 and Stat $5 \mathrm{a} / \mathrm{b}$ appear to have opposing roles in the regulation of Foxp3.

These two studies give new insights in the regulation of the immune system by GH. The first study, although small and open-label, examined the effect of hGH in HIV-infected patients. The main observations were that $\mathrm{GH}$ increased thymus size and increased de novo CD4+ T-cell production. The increase in TRECs (T-cell receptor rearrangement excision circle) also reflects increased thymic function. These data are especially interesting since they could suggest that pharmacological inhibition of thymic age-related or pathology-related involution may be possible.

The second paper is of interest because it shows an important role for Stat 5 in the regulation of Fox3p. Why is that important? It may help in the understanding of the consequences of human STAT5 mutations. Most of the few children described with STAT5B mutations are not only GH resistant, but have additional immune phenotypes, mostly probable autoimmune disease (arthritis, pneumonitis). Fox $3 p$ has a critical role in the regulation of autoimmune disease. Fox $3 p$ is necessary and sufficient for the development of T-regulatory cells. These cells are a subset of CD4+CD25+ cells that suppress T-cell proliferation and function and attenuate immune responses against self- or non-self-antigens. As a result, Fox3p-I- mice develop severe autoimmune disease. This paper shows that Stat5 is needed for optimal induction of Fox3p and that Stat5 binds directly to the Fox3p gene.

\section{New hope - New therapies for the future}

\section{Rescue of pituitary function in a mouse model of isolated growth hormone deficiency type II by RNA interference}

Shariat N, Ryther RC, Phillips JA 3rd, Robinson IC, Patton JG

Department of Biological Sciences, Vanderbilt University, Nashville, Tenn., USA

Endocrinology 2008;149:580-586

Background: Splicing mutations in the human GH (hGH) gene $(\mathrm{GH}-1)$ that cause skipping of exon 3 result in an autosomal dominant form of GH deficiency termed isolated GH deficiency type II (IGHD II). The GH-1 gene contains five exons: skipping of exon 3 results in transcripts encoding a $17.5-\mathrm{kDa}$ isoform 
that acts in a dominant-negative fashion to block secretion of the wild-type $22 \mathrm{kDa}$ hormone. Apart from short stature, anterior pituitary hypoplasia may occur in IGHD II. IGHD II is treated by subcutaneous delivery of hGH, which can rescue stature but, does not inhibit pituitary hypoplasia. Direct destruction of transcripts encoding the dominant-negative $17.5-\mathrm{kDa}$ isoform should both rescue stature and prevent hypoplasia.

Methods: Here, the authors have used delivery of short hairpin RNAs to rescue a murine model of IGHD II by specifically targeting transcripts encoding the $17.5-\mathrm{kDa}$ hGH isoform using RNA interference.

Results: Short hairpin RNA targeting the exon 3 deleted hGH isoform successfully rescued IGHD II mice. Conclusion(s): This is the first example where a short hairpin RNA has been expressed to specifically degrade an incorrectly spliced transcript and rescue a dominant-negative disease phenotype in vivo.

Patients with IGHD type II may develop anterior pituitary hormone deficiencies other than GH deficiency [10]. A transgenic mouse model overexpressing the exon 3 deleted $17.5 \mathrm{kDa}$ hGH isoform in somatotrophs (IGHD II mice) has shown death of somatotrophs due to clumping of non-secreted $17.5 \mathrm{kDa} \mathrm{GH}$ and subsequent destruction of cells neighboring dying somatotrophs, resulting in multiple hormone deficiencies [11]. This study tackled the fundamental cause of this pathology. RNA interference has not just been used to decrease the production of targeted RNA, but also to rescue the phenotype of a dominant-negative disease. A short hairpin RNA (shRNA) was designed complementary to the exon 2-exon 4 junction, unique to the exon 3 deleted hGH isoform. This shRNA successfully reduced transcript levels of the naturally occurring exon 3 deleted $\mathrm{GH}$ isoform, but not the full-length GH isoform [12]. The authors generated a transgenic mouse model expressing the shRNA which showed no obvious phenotype. These mice were then crossed to the IGHD II mice and indeed the amount of transgenic $17.5 \mathrm{kDa}$ GH production was reduced in these double transgenic mice. In contrast to IGHD II mice, $\mathrm{mGH}$ was detectable and rescued the phenotype of the IGHD II mice in terms of growth, anterior pituitary hypoplasia, and somatotroph morphology. Although this type of gene therapy is not suitable for treating human disease, such experiments show that RNA interference may be used in the treatment of dominant-negative disease.

\section{Food for thought}

\section{Nuclear targeting of the growth hormone receptor results in dysregulation of cell proliferation and tumorigenesis}

Conway-Campbell BL, Wooh JW, Brooks AJ, Gordon D, Brown RJ, Lichanska AM, Chin HS, Barton CL, Boyle GM, Parsons PG, Jans DA, Waters MJ

Institute for Molecular Bioscience and School of Biomedical Sciences, University of Queensland, Brisbane, Qld., Australia Proc Natl Acad Sci USA 2007;104:13331-13336

Background: The growth hormone receptor (GHR) has been demonstrated to be nuclear localized both in vivo and in vitro, but the significance of this observation has remained unknown. Here the authors show that nuclear GHR is strongly correlated with proliferative status in vivo by using a liver regeneration model.

Methods: In vitro experiments were used in which $\mathrm{BaF} / 3$ cells, a pro-B cell line, were transfected with GHR containing a nuclear localization sequence (NLS). Hepatectomized rats were used to study hepatic regeneration in vivo whereas tumorigenesis was studied in nude mice injected with NLS-GHRtransfected $\mathrm{BaF} / 3$ cells. Microarrays were used to study gene regulation in these experiments.

Results: In vitro, nuclear translocation of the GH receptor is $\mathrm{GH}$-dependent and appears to be mediated by the Importin system. Constitutive nuclear targeting of GHR in murine pro-B cells is associated with constitutive activation of Stat 5 . This activation is abrogated by inhibition of JAK2 and appears to be driven by autocrine murine GH action coupled with enhanced nuclear uptake of phospho-Stat5. Nuclear targeting induces dysregulated cell cycle progression in the pro-B cell line, associated with constitutive up-regulation of the proliferation inducers Survivin and Mybbp, the metastasis related Dysadherin, and other tumor markers. GHR nuclear-targeted cells generate metastatic tumors when injected into nude mice, which display nuclear localized GHR. 
Conclusion(s): Aberrant nuclear localization of GHR is a marker of high proliferative status and is sufficient to induce tumorigenesis and tumor progression.

It has been suggested that otherwise membrane-bound GHR as well as GHBP can be localized in the nucleus, for example in growth plate chondrocytes and cells in the gastrointestinal tract [13, 14], but also in breast tumor cells [15], which we now know also often contain Stat5, and that cellular internalization of GHR occurs after GH stimulation in vitro [16]. However, the role of nuclear GHR is unknown; after all, GHR exerts its function through its JAK-Stats signaling mechanism, and internalization has been considered by most investigators as part of protein degradation mechanism. Indeed, GH has been among the first proteins to have been shown to bind ubiquitin as a protease marker. This paper suggests that the presence of nuclear GHR is related to a high cellular proliferation rate. During liver regeneration, a higher proportion of cells contained nuclear GHR, and GHR colocalized with PCNA, a marker for proliferating cells. Constitutive nuclear GHR localization in BaF/3 cells was achieved by transfection with a GHR construct that contained a 'nuclear localization sequence' (NLS) that the wild-type GHR gene does not have. The authors showed that such transfection resulted both in vitro and in vivo, after injection of these cells into nude mice, in an increased proliferation rate. Microarray analysis supported these findings by showing an increase in expression of genes involved in cell proliferation. Stat5 phosphorylation was increased in cells expressing NLS-GHR and this is in line with increased Stat5 phosphorylation found in some tumors, but intriguingly, stimulation by $\mathrm{GH}$ and JAK activation still appeared to be necessary to induce proliferation in the cells that expressed constitutive nuclear GHR. This study suggests that constitutive prolonged presence of NLS-GHR in the nucleus is linked to increased proliferation. Follow-up experiments examining whether blocking nuclear transport of GHR will reduce proliferation will be of great importance.

\section{The 23K variant of the R23K polymorphism in the glucocorticoid receptor gene protects against postnatal growth failure and insulin resistance after preterm birth}

Finken MJJ, Meulenbelt I, Dekker FW, Frolich M, Romijn JA, Slagboom PE, Wit JM on behalf of the Dutch POPS-19 Collaborative Study Group

Department of Paediatrics, Leiden University Medical Center, Leiden, The Netherlands

m.j.j.finken@lumc.nl

J Clin Endocrinol Metab 2007;92:4777-4782

Background: Preterm birth is associated with postnatal growth failure, abdominal fat accumulation, insulin resistance, and hypertension, suggestive of increased glucocorticoid bioactivity. The R23K and N363S polymorphisms in the glucocorticoid receptor (GR) gene are associated with decreased and increased sensitivity to cortisol.

Methods: The effects of the R23K and N363S polymorphisms in the glucocorticoid receptor gene on linear growth and metabolic profile were studied in a cohort of men and women $(n=249)$ born $<32$ gestational weeks (Dutch Project on Preterm and Small for Gestational Age Infants cohort) and followed up prospectively from birth until 19 years of age.

Results: The $23 \mathrm{~K}$ variant $(\mathrm{n}=24)$ was associated with lower fasting insulin concentrations and a lower homeostatic model assessment (HOMA) for insulin resistance index as well as with taller stature from the age of 1 year onward. 23K carriers showed complete catch-up growth between the age of 3 and 12 months, and attained height was similar to the population reference mean, whereas stature in non-carriers was on average 0.5 SDS below the mean. In contrast, the N363S showed no different results.

Conclusion(s): Carriers of the $23 \mathrm{~K}$ variant seem to be protected, at least partially, against postnatal growth failure and insulin insensitivity after preterm birth.

Preterm birth can have lifelong sequelae such as growth failure, visceral obesity and insulin resistance, and has also been associated with long-term changes in the hypothalamo-pituitary-adrenal axis. Increased glucocorticoid action leads to obesity and insulin insensitivity and it has been previously shown that the R23K polymorphism of the GR is associated with reduced glucocorticoid bioactivity and a favorable metabolic profile in adults [17]. In addition, GR are necessary for normal growth [18], but increased glucocorticoid action has a negative impact on growth. Because the long-term consequences of preterm birth resemble increased glucocorticoid action, a cohort of preterm born adolescents was 
investigated for GR polymorphisms. This paper shows the potential importance of the $23 \mathrm{~K}$ polymorphism in the GR on the phenotype of insulin insensitivity and postnatal growth. The polymorphism occurred in $10 \%$ of the premature infants, and it would be important to investigate a cohort of SGA infants for similar correlations.

\section{Variable phenotypes in familial isolated growth hormone deficiency caused by a G6664A mutation in the GH-1 gene}

Hess O, Hujeirat Y, Wajnrajch MP, Allon-Shalev S, Zadik Z, Lavi I, Tenenbaum-Rakover Y

Pediatric Endocrine Unit, Ha' Emek Medical Center, Afula, Israel

rakover_y@clalit.org.il

J Clin Endocrinol Metab 2007;92:4387-4393

Background: The $\mathrm{G}$ to A transition at position 6664 (G6664A) in human $\mathrm{GH}-1$ results in the substitution of arginine by histidine at position $183(\mathrm{R} 183 \mathrm{H})$ of the $\mathrm{GH}$ molecule and causes familial isolated $\mathrm{GH}$ deficiency type II (IGHD II), a dominant-negative form of GHD.

Methods: The aim of the study was to investigate the phenotype-genotype correlation of subjects affected with IGHD II caused by a G6664A mutation. 66 subjects from two core families were included, of whom 34 were affected. The G6664A mutation among family members was determined by restriction fragment length polymorphism.

Results: 24 of the 52 members from family 1 and 10 of 14 from family 2 carried the same G6664A mutation in a heterozygous state. The affected subjects in family 1 were significantly shorter $[-2.6$ vs. -0.1 SD score (SDS), $\mathrm{p}=0.0001$ ] and had significantly lower IGF1 serum levels $(-1.9$ vs. -0.5 SDS, $\mathrm{p}=0.0001)$, compared with normal-genotype family members. The affected adults exhibited great variability in their stature, ranging from -4.5 to -1.0 (mean -2.8 SDS), with 5 members being of normal height (>-2 SDS). 12 children were diagnosed with IGHD. Two affected children had normal peak $\mathrm{GH}$ levels, although 1 of these subsequently demonstrated GH insufficiency $(6.5$ and $3.7 \mathrm{ng} / \mathrm{ml})$. The affected children from both families exhibited large variability in their height, growth velocity, delay in bone age, age at diagnosis, peak GH response, and IGF1 levels.

Conclusion(s): These detailed phenotypic analyses show the variable expressivity of patients bearing a G6664A mutation, reflecting the spectrum of GH deficiency in affected patients, even within families, and the presence of additional genes modifying height determination. These findings raise a new dilemma in the guidelines for the diagnosis of GH deficiency and the indications for GH therapy.

This is an important study as it shows that GH1 gene mutations can be associated with marked variability in auxological and biochemical data. Some individuals manifested normal height with a normal growth velocity. This brings into question the whole diagnosis of GHD. Individuals with mutations in the gene that encode growth hormone can have heights within the normal range, and so it would appear to be extremely difficult to convincingly exclude this diagnosis in short children. The study suggests that a combination of auxological, biochemical, neuroradiological and genetic data is required to make a diagnosis of GHD.

\section{Functionally significant insulin-like growth factor 1 receptor mutations in centenarians}

Suh Y, Atzmon G, Cho MO, Hwang D, Liu B, Leahy DJ, Barzilai N, Cohen P

Departments of Medicine and Molecular Genetics, Albert Einstein College of Medicine, Bronx, N.Y., USA

Proc Natl Acad Sci USA 2008;105:3438-3442

Background: Animal models suggest that lifespan can be actively modulated by components of the insulin/IGF1 pathway. Loss-of-function mutations in the GH/IGF1 pathway are associated with extended lifespan in yeast, worms, flies and mice.

Methods: The authors have studied the biochemical, phenotypic and genetic variations in IGF1 and $I G F 1 R$ in a cohort of Ashkenazi Jewish centenarians ( $\mathrm{n}=384, \mathrm{M}: \mathrm{F} 98: 286)$, their offspring $(\mathrm{n}=288$, M:F 174:114), and matched controls ( $\mathrm{n}=312, \mathrm{M}: \mathrm{F} 134: 178$, mean age 79.5 years).

Results: Female offspring showed 35\% higher serum IGF1 concentrations and were $2.5 \mathrm{~cm}$ shorter compared with controls, suggesting a possible alteration in the GH/IGF pathway in the longevity of females. 
This effect was not observed in male offspring. Sequence analysis of the IGF1 and IGF1 receptor (IGF1R) genes of female centenarians showed overrepresentation of heterozygous mutations in the IGF1R gene among centenarians relative to controls that are associated with high serum IGF1 levels and reduced activity of the IGF1R as measured in transformed lymphocytes.

Conclusion(s): Genetic alterations in the human IGF1R that result in altered IGF signaling pathway, confer an increase in susceptibility to human longevity, suggesting a role of this pathway in modulation of human lifespan.

In mice, loss-of-function mutations of the GH/IGF1 pathway are associated with dwarfism, numerous indices of delayed aging, enhanced stress resistance and a major increase in lifespan. Caloric restriction, which is associated with life extension and retardation of aging-related pathology, is also associated with a reduction in circulating IGF1 concentrations. On the other hand, whilst reduced IGF1 concentrations are protective against cancer, they constitute a risk factor for cardiovascular disease and diabetes. Moreover, human aging is associated with a reduction in GH and IGF1 concentrations, and it has been suggested that GH therapy may reverse some of the features of aging. Hence the role of IGF signaling in human longevity remains unclear.

In this study a subset of female centenarians with heights below the mean for the population $(n=79)$ and female controls $(n=161)$ was screened for all possible genetic variations throughout the coding regions and splice junctions of the IGF1 and IGF1R genes by using 2D gene scanning and DNA sequencing. No variations were identified in IGF1, however 20 sequence variations, of which 9 were novel, were identified in the IGF1R gene. Five were in the coding region, and four of these were found in centenarians with short stature and elevated concentrations of IGF1. None of the offspring of the centenarian mutation carriers harbored these rare mutations. The entire cohort (384 centenarians and 312 controls) were screened for the A37T and R407H mutations. Nine centenarians $(2.3 \%)$ carried the A37T $(n=2)$ or the R407H $(n=7)$ mutations, whereas only 1 control $(0.3 \%)$ carried a mutation $(\mathrm{R} 407 \mathrm{H})$. Hence, the mutations were significantly commoner in the centenarians. Within the centenarian group, the mutation carriers had significantly higher IGF1 concentrations than the non-mutation carriers, and were slightly shorter, although the latter did not reach statistical significance. Immortalized lymphocytes from carriers of A37T, R407H, and T470T revealed reduced IGF1R levels and reduced AKT phosphorylation compared with the centenarian non-carriers.

These data suggest that genetic alterations in the human IGF1R that result in altered IGF signaling may confer an increased lifespan, suggesting a role of the GH/IGF1 pathway in human longevity. This study provides interesting data associating the GH-IGF1 axis to longevity. The association has been previously described, e.g. in the GH-deficient Ames dwarf mice and patients with PROP1 deficiency $[19,20]$. However, there is controversy surrounding the issue [21]. The data would need confirmation in larger cohorts, but nevertheless are tantalizing.

\section{Juvenility in the context of life history theory}

\section{Hochberg Z}

Meyer Children's Hospital, Rambam Medical Center and Technion-Israel Institute of Technology, Haifa, Israel z_hochberg@rambam.health.gov.il

Arch Dis Child 2008;93:534-539

Background: Homo sapiens is unique in having four prolonged and pronounced postnatal pre-adult life history stages: infancy (duration 30-36 months; ends with weaning from breastfeeding in traditional societies); childhood (lasts for an additional 2-4 years, concludes with some independence in terms of protection and food provision); a juvenile stage (duration 3-4 years, terminates with readiness for sexual maturation), and adolescence (duration 3-5 years, culminates in fertility). Juvenility is characterized by two transitional periods, experienced only by humans: a transition from childhood to juvenility and from juvenility to adolescence. Juvenility, 'the age of reason and responsibility' and concrete operation, coincides with elementary school age and offers opportunities to prepare for the social complexity of adolescence.

Methods and Results: This review describes the transition to juvenility as defined by three variables: adrenarche (the onset of adrenal androgen generation), growth pattern (decelerating from a linear childhood growth velocity) and adiposity rebound acceleration of body mass index.

Conclusion(s): The transition from childhood to juvenility marks a period of change in the life history of an individual from total dependence on the family and tribe for provision and security to self-supply. The 
transition is characterized by a predictive adaptive response of body composition and energy metabolism. The transition from juvenility to adolescence is marked by adaptation to energy resources, other environmental cues, the social needs of adolescence, and their maturation to directly determine fitness. The data presented suggest that this period is endowed with programming/predictive adaptive responses of body composition to the environment.

This is a thought-provoking review that dissects the early life history of humans into four postnatal and pre-adult stages. Apart from humans, all other mammals transition directly from infancy to juvenility, and then directly to adulthood without passing through the childhood and adolescence phases. The various phases are associated with complex neurological and physical changes. The author suggests that in evolutionary terms, the onset of juvenility is associated with the eruption of permanent molars, and that this is highly associated with brain weight. Changes in adrenal androgen secretion are associated with corresponding changes in the body composition, and in cognition. In particular, the phenomenon of adiposity rebound may be the first clinical sign of juvenility, and may mark the early onset of obesity in those that are predisposed to it. DHEAS levels correlate positively with increases in BMI. The importance of this phenomenon cannot be underestimated in the context of a global increase in obesity.

\section{References}

1. Nagel BH, Mortier W, Elmlinger M, Wollmann HA, Schmitt K, Ranke MB: Short stature in Duchenne muscular dystrophy: a study of 34 patients. Acta Paediatr 1999;88:62-65.

2. Gao Q, Wolfgang MJ, Neschen S, Morino K, Horvath TL, Shulman GI, et al: Disruption of neural signal transducer and activator of transcription-3 causes obesity, diabetes, infertility, and thermal dysregulation. Proc Natl Acad Sci USA 2004;101:4661-4666.

3. Ikeda A, Chang KT, Matsumoto Y, Furuhata Y, Nishihara M, Sasaki F, et al: Obesity and insulin resistance in human growth hormone transgenic rats. Endocrinology 1998;139:3057-3063.

4. Mori H, Hanada R, Hanada T, Aki D, Mashima R, Nishinakamura H, et al: Socs3 deficiency in the brain elevates leptin sensitivity and confers resistance to diet-induced obesity. Nat Med 2004;10:739-743.

5. Gevers E, Hindmarsh P, Dattani M: Growth and growth factors; in Carel J-C, Hochberg Z (eds): Yearbook of Pediatric Endocrinology 2007. Basel, Karger, 2007, pp 33-51.

6. Wang HG, Miyashita T, Takayama S, Sato T, Torigoe T, Krajewski S, et al: Apoptosis regulation by interaction of Bcl-2 protein and Raf-1 kinase. Oncogene 1994;9:2751-2756.

7. Lettre G, Jackson AU, Gieger C, Schumacher FR, Berndt SI, Sanna S, et al: Identification of ten loci associated with height highlights new biological pathways in human growth. Nat Genet 2008;40:584-591.

8. Gudbjartsson DF, Walters GB, Thorleifsson G, Stefansson H, Halldorsson BV, Zusmanovich P, et al: Many sequence variants affecting diversity of adult human height. Nat Genet 2008;40:609-615.

9. Binder G, Seidel AK, Martin DD, Schweizer R, Schwarze CP, Wollmann HA, et al: The endocrine phenotype in SilverRussell syndrome is defined by the underlying epigenetic alteration. J Clin Endocrinol Metab 2008;93:1402-1407.

10. Salemi S, Yousefi S, Baltensperger K, Robinson IC, Eble A, Simon D, et al: Variability of isolated autosomal dominant GH deficiency (IGHD II): impact of the P89L GH mutation on clinical follow-up and GH secretion. Eur J Endocrinol 2005; 153:791-802.

11. McGuinness L, Magoulas C, Sesay AK, Mathers K, Carmignac D, Manneville JB, et al: Autosomal dominant growth hormone deficiency disrupts secretory vesicles in vitro and in vivo in transgenic mice. Endocrinology 2003;144:720-731.

12. Ryther RC, Flynt AS, Harris BD, Phillips JA 3rd, Patton JG: GH1 splicing is regulated by multiple enhancers whose mutation produces a dominant-negative GH isoform that can be degraded by allele-specific small interfering RNA (siRNA). Endocrinology 2004;145:2988-2996.

13. Gevers EF, van der Eerden BC, Karperien M, Raap AK, Robinson IC, Wit JM: Localization and regulation of the growth hormone receptor and growth hormone-binding protein in the rat growth plate. J Bone Miner Res 2002;17:1408-1419.

14. Lobie PE, Breipohl W, Waters MJ: Growth hormone receptor expression in the rat gastrointestinal tract. Endocrinology 1990;126:299-306.

15. Mertani HC, Garcia-Caballero T, Lambert A, Gerard F, Palayer C, Boutin JM, et al: Cellular expression of growth hormone and prolactin receptors in human breast disorders. Int J Cancer 1998;79:202-211.

16. Lobie PE, Wood TJ, Chen CM, Waters MJ, Norstedt G: Nuclear translocation and anchorage of the growth hormone receptor. J Biol Chem 1994;269:31735-31746.

17. Van Rossum EF, Koper JW, Huizenga NA, Uitterlinden AG, Janssen JA, Brinkmann AO, et al: A polymorphism in the glucocorticoid receptor gene, which decreases sensitivity to glucocorticoids in vivo, is associated with low insulin and cholesterol levels. Diabetes 2002;51:3128-3134.

18. Tronche F, Opherk C, Moriggl R, Kellendonk C, Reimann A, Schwake L, et al: Glucocorticoid receptor function in hepatocytes is essential to promote postnatal body growth. Genes Dev 2004;18:492-497.

19. Krzisnik C, Kolacio Z, Battelino T, Brown M, Parks J, Laron Z: The 'little people' of the island of Krk - revisited. Etiology of hypopituitarism revealed. J Endocr Genet 1999;1:9-19.

20. Bartke A, Brown-Borg H: Life extension in the dwarf mouse. Curr Top Dev Biol 2004;63:189-225.

21. Besson A, Salemi S, Gallati S, Jenal A, Horn R, Mullis PS, et al: Reduced longevity in untreated patients with isolated growth hormone deficiency. J Clin Endocrinol Metab 2003;88:3664-3667. 